
НИТРАТА НАТРИЯ В ОРГАНИЗМ

\author{
Хмиль Д.А.(65723drums@gmail.com), Левков A.A. (levkov.anatolij@yandex.ru), \\ Костенко B.A. (kostenkol1711@rambler.ru) \\ Высшее государственное учебное заведение Украины \\ «Украинская медицинская стоматологическая академия», Полтава, Украина
}

\begin{abstract}
Цель: изучение влияния сочетанного действия L-аргинина и ингибитора ядерного фактора $\kappa B$ (NF-кB) на процессы коллагенолиза и деполимеризации протеогликанов в коже бельх крыс и её биомеханические свойства при избыточном поступлении нитрата натрия в организм.

Материал и методы. В эксперименте на 35 бельх крысах линии Вистар оценивали концентрацию продуктов коллагенолиза (свободного оксипролина) и деполимеризации протеогликанов (гексуроновых кислот) в гомогенате кожи, а также её тензометрические характеристики.

Результаты. Выявлено, что 30-дневное введение нитрата натрия в организм крыс сопровождается в коже усилением процессов коллагенолиза и деполимеризации протеогликанов, нарушением биомеханических характеристик кожи (прочности и эластичности). Сочетанное введение L-аргинина (500 мг/кг/сут) и ингибитора NF-кB аммония пирролидиндитиокарбамата (PDTC, 76 мг/кг), 1 раз в 3 дня, начиная с 15-х суток нитратной интоксикации, в большей степени, по сравнению с изолированнылм применением, уменьшает кониентрацию свободного оксипролина и гексуроновых кислот в гомогенате кожи, улучшает тензометрические показатели кожи.

Bblводы. Сочетанное действие L-аргинина и PDTC в условиях нитратной интоксикации более эффективно по сравнению с изолированным применением этих веществ, ограничивает дезорганизацию соединительной ткани кожи, улучшает её биомеханические свойства.
\end{abstract}

Ключевые слова: интоксикация нитратами, ичикл оксида азота, коллагенолиз, деполимеризация протеогликанов, кожа.

\section{Введение}

Загрязнение нитратами воды и почвы в настоящее время расценивается как глобальная экологическая проблема. На 43\% территории стран Европы концентрация нитратов в грунтовых водах составляет 25-50 мг/л, на 25\% территории - более 50 мг/л [1].

Типовым механизмом действия нитратов считается их восстановление до нитрит-ионов, а тех, в свою очередь, - до оксида азота (NO) с риском развития окислительно-нитрозативного стресса вследствие образования активных метаболитов (пероксинитрит, диоксид азота и др.) [2-5]. Следствием этого, по данным литературы, является дезорганизация соединительной ткани разных органов (костей, пародонта), связанная с деполимеризацией коллагена, гликопротеинов и протеогликанов $[6,7]$.

Основным белком соединительной ткани кожи, обеспечивающим её упругость и эластичность, является коллаген [8]. Эта макромолекула имеет уникальный аминокислотный состав - $33 \%$ глицина и около $20 \%$ пролина и оксипролина. Именно увеличение концентрации последнего в тканях расценивается как маркёр коллагенолиза. Другим важным компонентом соединительной ткани кожи являются протеогликаны - высокомолекулярные агрегаты, состоящие из субъединиц гликозаминогликанов и белкового ядра, объединённых трисахаридным звеном. Они обеспечивают механические и барьерные свойства кожи, её тургор, участвуют в обмене воды и солей, выполняют ряд других важных функций [9].

Недавно установлено, что в условиях чрезмерной экзогенной нагрузки донаторами NO нарушается механизм ауторегуляции его образования в тканях («цикл оксида азота»), что приводит к избыточной активации индуцибельной NO-синтазы (iNOS) $[2,10]$. В то же время конституционные изоформы этого фермента (например нейрональная) ограничивают проявления окислительно-нитративного стресса, оказывая тормозное влияние на опосредованную ядерным фактором кB (NF-кB) экспрессию iNOS [11].

В последнее время установлено, что введение ингибиторов NF-кB сопровождается повышением антиоксидантного и коллагенопротективного действия субстрата NOS и аргиназы - L-аргинина - в разных органах (пародонт, слюнные железы) $[6,12]$.

Однако эффективность сочетанного применения L-аргинина и ингибиторов NF-кB для коррекции дезорганизации соединительной ткани кожи в условиях избыточного образования оксида азота из экзогенных источников (модель хронической интоксикации нитратом натрия) остается невыясненной.

Целью работы было изучение влияния сочетанного действия L-аргинина и ингибитора NF-кB на маркёры коллагенолиза и деполимеризации протеогликанов в коже белых крыс и её биомеханические свойства при избыточном поступлении нитрата натрия в организм. 


\section{Материал и методы}

Исследования были проведены на 35 белых крысах линии Вистар массой 180-220 г в пяти сериях опытов: в первой - интактные животные (контрольная серия), во второй - 30-дневная интоксикация нитратом натрия, в остальных - начиная с 15 дня интоксикации, крысам вводили следующие вещества (все - производства Sigma-Aldrich, США): в третьей серии - L-аргинин, в четвертой - ингибитор активации NF-кB - аммония пирролидиндитиокарбамат (PDTC ammonium pyrrolidinedithiocarbamate), в пятой L-аргинин и PDTC.

Нитрат натрия вводили внутрижелудочно с помощью зонда в дозе 200 мг/кг массы тела в виде водного раствора. Использование этой методики позволяет воспроизвести избыточное образование и депонирование NO в коже в виде парамагнитных комплексов с гемовым и негемовым железом [3]. PDTC и L-аргинин назначали в дозе 76 мг/кг массы [13] и 500 мг/кг [6], внутрибрюшинно, 1 раз в 3 дня, соответственно.

Животных декапитировали под эфирным наркозом. Стандартные образцы кожи вырезали из области спины. Комиссией по вопросам биомедицинской этики Высшего государственного учебного заведения Украины «Украинская медицинская стоматологическая академия» (протокол № 148 от 24.11.2016 г.) нарушений морально-этических норм при проведении научно-исследовательской работы не выявлено.

Состояние коллагена и протеогликанов определяли по содержанию в гомогенате кожи свободного оксипролина [14] и гексуроновых кислот [15].
Биомеханические характеристики кожи оценивали на основании исследования разрывной нагрузки и относительного удлинения стандартного образца кожи спины $(5 \times 2$ см) [16].

Полученные данные подвергали статистической обработке. Для проверки распределения на нормальность применяли расчет критерия Шапиро-Уилка. Поскольку данные соответствовали нормальному распределению, для их сравнения использовали t-критерий Стьюдента для независимых выборок. Для преодоления проблемы множественных сравнений применяли поправку Бонферрони. Статистические расчеты проводили с использованием программы "StatisticSoft $6.0^{\prime \prime}$.

\section{Результаты и обсуждение}

Воспроизведение 30-дневной интоксикации нитратом натрия сопровождается повышением содержания в тканях кожи свободного оксипролина и гексуроновых кислот (см. табл.) соответственно, на $66,5 \%(\mathrm{p}<0,001)$ и в 2,4 раза $(\mathrm{p}<0,001)$, что указывает на существенную активацию в дерме процессов коллагенолиза и деполимеризации гликозаминогликанов.

Эти изменения закономерно приводят к нарушениям биомеханических свойств кожи. Отмечается снижение величины разрывной нагрузки на $19,1 \%(p<0,001)$, что характеризует уменьшение механической прочности кожи. Величина относительного удлинения снижается на 16,5\% $(\mathrm{p}<0,001)$, что отражает уменьшение эластичности исследуемых образцов кожи.

Известно, что именно протеогликановый компонент матрикса соединительной ткани изза наличия полианионных свойств обеспечива-

Таблица - Сочетанное влияние L-аргинина и ингибитора активации NF-кB PDTC на маркёры дезорганизации соединительной ткани кожи и её биомеханические свойства $(\mathrm{M} \pm \mathrm{m}, \mathrm{n}=35)$

\begin{tabular}{|c|c|c|c|c|c|}
\hline \multirow{3}{*}{ Показатели } & \multicolumn{5}{|c|}{ Серии опытов } \\
\hline & \multirow{2}{*}{$\begin{array}{l}\text { Интактные } \\
\text { животные }\end{array}$} & \multicolumn{4}{|c|}{ Введение нитрата натрия (30 дней) } \\
\hline & & Контроль & +1-аргинин & + pdtc & + 1-аргинин + pdtc \\
\hline $\begin{array}{l}\text { Свободный } \\
\text { оксипролин, } \\
\text { мкмоль/г }\end{array}$ & $4,00 \pm 0,24$ & $6,66 \pm 0,16 *$ & $5,52 \pm 0,29 * / * *$ & $5,30 \pm 0,17 * / * *$ & $3,57 \pm 0,14 * * / * * * / * * * *$ \\
\hline $\begin{array}{l}\text { Гексуроновые } \\
\text { кислоты, мкмоль/г }\end{array}$ & $20,82 \pm 2,88$ & $50,08 \pm 1,69 *$ & $\begin{array}{c}39,87 \pm 3,35 \\
* / * *\end{array}$ & $5,43 \pm 0,26 * / * *$ & $27,50 \pm 1,30 * * / * * * / * * * *$ \\
\hline $\begin{array}{l}\text { Разрывная нагрузка } \\
\text { образца кожи, н }\end{array}$ & $83,9 \pm 0,7$ & $67,9 \pm 1,4 *$ & $73,4 \pm 1,3 * / * *$ & $76,8 \pm 1,0 * / * *$ & $82,6 \pm 1,5 * * / * * * / * * * *$ \\
\hline $\begin{array}{l}\text { Относительное } \\
\text { удлинение образца } \\
\text { кожи, \% }\end{array}$ & $18,2 \pm 0,6$ & $15,2 \pm 0,2 *$ & $15,8 \pm 0,4 *$ & $16,8 \pm 0,3 * *$ & $18,1 \pm 0,1 * * / * * * / * * * *$ \\
\hline
\end{tabular}

Примечание: *-p<0,05 по сравнению с данными интактной группь, ** - p<0,05 по сравнению с данными второй серии, ***_p $<0,05$ по сравнению с данными третьей серии, **** - $<<0,05$ по сравнению с данными четвертой серии 
ет прочность кожи на сжатие, её способность деформироваться и преодолевать деформацию, восстанавливать своё гидратированное состояние [8].

Введение L-аргинина в условиях эксперимента уменьшает в коже содержание свободного оксипролина и гексуроновых кислот, соответственно, на $17,1 \%(\mathrm{p}<0,01)$ и на $20,4 \%(\mathrm{p}<0,02)$ по сравнению с данными второй серии. При этом величина разрывной нагрузки возрастает на $8,1 \%(\mathrm{p}<0,02)$ по сравнению с данными второй серии, что свидетельствует о повышении механической прочности кожи. Величина удлинения образцов кожи существенно не отличается от данных второй серии.

Введение PDTC в условиях эксперимента уменьшает в коже содержание свободного оксипролина и гексуроновых кислот - соответственно, на 20,4\% $(\mathrm{p}<0,001)$ и 24,7\% $(\mathrm{p}<0,01)$ по сравнению с данными второй серии. Величины разрывной нагрузки и относительного удлинения повышаются, соответственно, на 13,1\% $(\mathrm{p}<0,001)$ и $10,5 \%(\mathrm{p}<0,001)$ по сравнению с данными второй серии.

Полученные результаты подтверждают роль $\mathrm{NF}-\kappa \mathrm{B}$ в активации коллагенолиза и деполимеризации протеогликанов в дерме, а также нарушении прочности и эластичности кожи при избыточном поступлении нитрата натрия в организм крыс.

Сочетанное применение L-аргинина и PDTC в условиях эксперимента сопровождается снижением концентраций свободного оксипролина и гексуроновых кислот, которые, соответственно, на $46,4 \%(\mathrm{p}<0,001)$ и 45,1\% ( $<<0,001)$ уступают соответствующим показателям второй серии, на $35,3 \%(p<0,001)$ и $31,0 \%(p<0,01)-$ третьей серии, на $32,6 \%(\mathrm{p}<0,001)$ и $27,1 \%(\mathrm{p}<0,01)$ - четвертой серии.

При этом величины разрывной нагрузки и относительного удлинения образцов кожи на $21,6 \% \quad(p<0,001)$ и $19,1 \% \quad(p<0,001)$, соответственно, превышают показатели второй серии, на $12,5 \%(\mathrm{p}<0,001)$ и $14,6 \%(\mathrm{p}<0,001)$ - третьей серии, на 7,6\% $(\mathrm{p}<0,01)$ и 7,7\% $(\mathrm{p}<0,01)$ - четвертой серии.

Таким образом, введение L-аргинина ограничивает деполимеризацию коллагена и протеогликанов, а также улучшает прочностные характеристики кожи. Поскольку данная аминокислота является субстратом NO-синтазы, эти изменения могут быть связаны с улучшением регионарной гемодинамики вследствие усиления выработки NO. Однако при избыточном поступлении в организм нитрата натрия вследствие ферментативного и неферментативного восстановления нитрат-ионов до нитрит-ионов, а тех, в свою очередь, - до NO, ткани не испытывают недостатка в последнем. В настоящее время нитрат- и нитрит-редуктазные реакции считаются резервным механизмом образования NO в условиях гипоксии [4-5].

По-видимому, выявленные нами изменения в большей мере связаны с образованием иных метаболитов L-аргинина. Известно, что конкурентом окислительного (NO-синтазного) пути обмена L-аргинина является неокислительный (apгиназный) путь, особенно в митохондриальном компартменте, где локализована высокоактивная индуцибельная изоформа аргиназы - аргиназа II, представленная в эндотелиальных клетках, кератиноцитах, фибробластах, макрофагах и нейтрофилах [17]. В аргиназном пути образуется ряд веществ, необходимых для жизнедеятельности организма - орнитин, цитруллин, глутамат, глутамин, глутатион, $\gamma$-аминомасляная кислота, креатин, полиамины и т. д. [18-20]. Орнитин является важным компонентом коллагена [19], полиамины регулируют процессы репликации и транскрипции ДНК, биосинтеза белка и пролиферации клеток [20].

Введение PDTC приводит к нарушению активации NF-кB на этапе деградации ингибиторного белка ІкВ под действием протеасомы [13], следствием этого является нарушение экспрессии многих генов, обеспечивающих процессы воспаления, иммунного ответа и апоптоза клеток, включая ген индуцибельной NO-синтазы, генерирующей микромолярные концентрации NO с цитотоксичными свойствами [21]. В этих условиях закономерно возрастает утилизация L-аргинина в аргиназном метаболическом пути с образованием указанных выше соединений, необходимых для поддержания барьерных свойств кожи.

Сочетанное применение экзогенного L-apгинина и ингибитора активации NF-кB особо важно при снижении активности ферментов аргиназного пути (аргиназы, орнитиндекарбоксилазы), выявленной в условиях избыточной нитратной нагрузки [22].

\section{Bblводы}

1. 30-дневное введение в организм белых крыс нитрата натрия сопровождается в тканях кожи усилением процессов коллагенолиза и деполимеризации протеогликанов, нарушением биомеханических характеристик кожи (прочности и эластичности).

2. Сочетанное действие L-аргинина и селективного ингибитора ядерного фактора $\kappa \mathrm{B}$ аммония пирролидиндитиокарбамата в условиях 30-дневной интоксикации нитратом натрия более эффективно по сравнению с изолированным применением этих веществ, улучшает регенераторные и биомеханические свойства тканей (ограничивает коллагенолиз и деполимеризацию гликозаминогликанов, увеличивает прочность и эластичность кожи).

\section{Литература}

1. Бутовский, Р. О. Проблемы химического загрязнения почв и грунтовых вод в странах Европейского Союза / Р. О. Бутовский // Агрохимия. - 2004. - № 3. - С.74-81.

2. Механізми ауторегуляції утворення оксиду азоту в організмі ссавців та їх порушення при розвитку патологічних процесів / В. О. Костенко [та ін.] // Актуальні 
проблеми сучасної медицини. - 2011. - Т. 11, № 3. C. $150-154$.

3. Механізми порушення окисних процесів у тканинах при надлишковому утворенні оксиду азоту з екзогенних попередників / В. О. Костенко [та ін.] // Клінічна та експериментальна патологія. - 2004. - Т. 3, № 2 (ч. 1). - С. 202-204.

4. Реутов, В. П. Механизм антирадикальной защиты клеток и организма в целом заложен в циклической организации тех метаболических процессов, которые сопряжены с образованием свободных радикалов / В П. Реутов // Патофізіологія і фармація: шляхи інтеграції : тези доповідей VII Національного конгресу патофізіологів України з міжнародною участю, (5-7 жовтня 2016 р.). - Харків : Вид-во НФаУ, 2016. - С. 191.

5. The nitrate-nitrite-nitric oxide pathway in physiology and therapeutics / J. O. Lundberg [et al.] // Nature reviews. 2008. - Vol. 7. - P. 156-167.

6. Ляшенко, Л. I. Роль NF-кB-опосередкованої дії NOсинтаз у дезорганізації сполучної тканини пародонта за умов експериментального метаболічного синдрому / Л. І. Ляшенко, В. О. Костенко // Загальна патологія та патологічна фізіологія. - 2013. - Т. 8, № 3. - С. 53-57.

7. Сорокін, Б. В. Зміни компонентів органічного матриксу кісткової тканини щурів при відтворенні експериментального остеопорозу за умов хронічної інтоксикації нітратом натрію / Б. В. Сорокін, В. О. Костенко // Актуальні проблеми сучасної медицини: Вісн. Української мед. стоматол. академії. - 2013. - Т. 13, № 2. - С. 220-224.

8. Морфофункциональная характеристика дермы кожи и её изменения при старении / С. С. Целуйко [и др.] // Бюллетень физиологии и патологии дыхания. - 2016. - № 60. - С. 111-116.

9. Зимницкий, А. Н. Гликозаминогликаны в биохимических механизмах адаптации организма к некоторым физиологическим и патологическим состояниям / А. Н. Зимницкий, С. А. Башкатов. - Москва : Фармацевтический бюллетень, 2004. - 235 с.

10. Akimov, O. Ye. Functioning of nitric oxide cycle in gastric mucosa of rats under excessive combined intake of sodium nitrate and fluoride / O. Ye. Akimov, V. O. Kostenko // Ukrainian Biochemical Journal. - 2016. Vol. 88, № 6. - P. 70-75.

11. Neuronal nitric oxide synthase (NOS) regulates the expression of inducible NOS in rat small intestine via modulation of nuclear factor kappa B / X.-W. Qu [et al.] // FASEB Journal. - 2001. - Vol. 15, № 2. - P. 439-446.

12. Нагорняк, І. В. Ефективність поєднаного застосування L-аргініну та інгібітора ядерного фактора кB для корекції вільнорадикальних процесів і функцій слинних залоз щурів за умов дії метилового ефіру метакрилової кислоти / І. В. Нагорняк, В. О. Костенко // Актуальні проблеми сучасної медицини. - 2015. - Т. 15, № 3 (ч. 1). - C. 221-225.

13. Effect of ammonium pyrrolidine dithiocarbamate (PDTC) on NF- $\kappa \mathrm{B}$ activation and CYP2E1 content of rats with immunological liver injury / J. D. Qin [et al.] // Pharmaceutical Biology. - 2014. - Vol. 52, № 11. - P. 1460-1466.

14. Тетянец, С. С. Метод определения свободного оксипролина в сыворотке крови / С. С. Тетянец // Лабораторное дело. - 1985. - № 1. - С. 61-62.

15. Метод определения гликозаминогликанов в биологических жидкостях / П. Н. Шараев [и др.] // Лабораторное дело. - 1987. - № 5. - С. 330-332.
16. Оренчук, О. П. Тензіометричні та репаративні властивості шкіри тварин за умов тривалого надходження в організм нітрату натрію / О. П. Оренчук // Аграрні вісті. - 2009. - № 1. - C. 36-38.

17. Role of arginine in superficial wound healing in man / I. B. Debats [et al.] // Nitric Oxide. - 2009. - Vol. 21, № 3-4. - P. 175-183.

18. Insights into the arginine paradox: evidence against the importance of subcellular location of arginase and eNOS / Sh. Elms [et al.] // American Journal of Physiology-Heart and Circulatory Physiology. - 2013. - Vol. 305, № 5. P. H651-H666.

19. Pawelec, K. M. Collagen: a network for regenerative medicine / K. M. Pawelec, S. M. Best, R. E. Cameron // Journal of Materials Chemistry. B, Materials for Biology and Medicine. - 2016. - Vol. 4, № 40. - P. 6484-6496.

20. Morris, S. M. Jr. Arginine metabolism: boundaries of our knowledge / S. M. Jr. Morris // The Journal of Nutrition. - 2007. - Vol. 137, № 6, (suppl. 2). - P. 1602S-1609S.

21. The nuclear factor kappa $B$ signaling pathway: integrating metabolism with inflammation / L. Tornatore [et al.] // Trends in Cell Biology. - 2012. - Vol. 22, № 11. - P. 557-566.

22. Хміль, Д. О. Роль NO-синтази і аргінази у механізмах окисно-нітративного стресу в шкірі щурів за умов надлишкового надходження в організм нітрату натрію / Д. О. Хміль, А. В. Міщенко, В. О. Костенко // Український журнал медицини, біології та спорту. 2017. - № 2. - С. 54-59.

\section{References}

1. Butovskij RO. Problemy himicheskogo zagrjaznenija pochv i gruntovyh vod v stranah Evropejskogo Sojuza. Agrohimija. 2004;3:74-81. (Russian).

2. Kostenko VO, Solovjova NV, Kovalenko OV, Levchenko OA, Sorokin BV, Stasjuk OA, Fartushna AM, Bogdanov OV. Mehanizmi autoreguljaciï utvorennja oksidu azotu v organizmi ssavciv ta ïh porushennja pri rozvitku patologichnih procesiv. Aktual'ni problemi suchasnoï medicini: 2011;11(3):150-154. (Ukrainian).

3. Kostenko VO, Kostenko AG, Denisenko CV. Mehanizmi porushennja okisnih procesiv $\mathrm{u}$ tkaninah pri nadlishkovomu utvorenni oksidu azotu z ekzogennih poperednikiv. Klinichna ta eksperimentalna patologija. 2004;3(2 pt 1):202-204. (Ukrainian).

4. Reutov VP. Mehanizm antiradikalnoj zashhity kletok i organizma $\mathrm{v}$ celom zalozhen $\mathrm{v}$ ciklicheskoj organizacii teh metabolicheskih processov, kotorye soprjazheny $\mathrm{s}$ obrazovaniem svobodnyh radikalov. In: Patofiziologija i farmacija: shljahi integraciï : tezi dopovidej VII Nacionalnogo kongresu patofiziologiv Ukraïni z mizhnarodnoju uchastju; 2016 zhovtnja 5-7; Harkiv. Kharkiv: NPhU; 2016. p. 191. (Russian).

5. Lundberg JO, Weitzberg E, Gladwin MT. The nitratenitrite-nitric oxide pathway in physiology and therapeutics. Nature reviews. 2008;7(2):156-167.

6. Ljashenko LI, Kostenko VO. Rol NF-kBoposeredkovanoï diï NO-sintaz u dezorganizaciï spoluchnoï tkaniniparodonta za umov eksperimentalnogo metabolichnogo sindromu. Zagalna patologija ta patologichna fiziologija. 2013;8(3):53-57. (Ukrainian).

7. Sorokin BV, Kostenko VO. Zmini komponentiv organichnogo matriksu kistkovoï tkanini shhuriv pri vidtvorenni eksperimentalnogo osteoporozu za umov hronichnoï intoksikaciï nitratom natriju. Aktual'ni problemi suchasnoï medicini: 2013;13(2):220-224. (Ukrainian). 
8. Celujko SS, Maljuk EA, Korneeva LS, Krasavina NP. Morfofunkcionalnaja harakteristika dermy kozhi i ejo izmenenija pri starenii. Bjulleten fiziologii i patologii dyhanija. 2016;60:111-116. (Russian).

9. Zimnickij AN, Bashkatov SA. Glikozaminoglikany v biohimicheskih mehanizmah adaptacii organizma $\mathrm{k}$ nekotorym fiziologicheskim i patologicheskim sostojanijam. Moscow: Farmacevticheskij bjulleten; 2004. 235 p. (Russian).

10. Akimov OYe, Kostenko VO. Functioning of nitric oxide cycle in gastric mucosa of rats under excessive combined intake of sodium nitrate and fluoride. Ukr. Biochem. $J$. 2016;88(6):70-75.

11. Qu XW, Wang H, De Plaen IG, Rozenfeld RA, Hsuen W. Neuronal nitric oxide synthase (NOS) regulates the expression of inducible NOS in rat small intestine via modulation of nuclear factor kappa B. FASEB $J$. 2001;15(2):439-446.

12. Nagornjak IV, Kostenko VO. Efektivnist poednanogo zastosuvannja L-argininu ta ingibitora jadernogo faktora $\kappa \mathrm{B}$ dlja korekciï vilnoradikal'nih procesiv i funkcij slinnih zaloz shhuriv za umov diï metilovogo efiru metakrilovoï kisloti. Aktual'ni problemi suchasnoï medicini. 2015;15(3 Pt 1):221-225. (Ukrainian).

13. Qin JD, Cao ZH, Li XF, Kang XL, Xue Y, Li YL, Zhang D, Liu XY, Xue YZ. Effect of ammonium pyrrolidine dithiocarbamate (PDTC) on NF- $\kappa$ B activation and CYP2E1 content of rats with immunological liver injury. Pharm. Biol. 2014;52(11):1460-1466.

14. Tetjanec SS. Metod opredelenija svobodnogo oksiprolina v syvorotke krovi. Laboratornoe delo.1985;1:61-62. (Russian).
15. Sharaev PN, Pishkov VN, Soloveva NI, Shirokova TJu, Soloveva TV, Zvorygina NG, Solopaev AA, Alekseeva NK. Metod opredelenija glikozaminoglikanov v biologicheskih zhidkostjah. Laboratornoe delo. 1987;5:330332. (Russian).

16. Orenchuk OP. Tenziometrichni ta reparativni vlastivosti shkiri tvarin za umov trivalogo nadhodzhennja $\mathrm{v}$ organizm nitratu natriju. Agrarni visti. 2009;1:36-38. (Ukrainian).

17. Debats IB, Wolfs TG, Gotoh T, Cleutjens JP, PeutzKootstra CJ, van der Hulst RR. Role of arginine in superficial wound healing in man. Nitric Oxide. 2009; 21(3-4):175-183.

18. Elms Sh, Chen F, Wang Y, Qian J, Askari B, Yu Ya, Pandey D, Iddings J. Insights into the arginine paradox: evidence against the importance of subcellular location of arginase and eNOS. Am. J. Physiol. Heart Circ. Physiol. 2013;305(5):H651-H666.

19. Pawelec KM, Best SM, Cameron RE. Collagen: a network for regenerative medicine. J. Mater. Chem. B. Mater. Biol. Med. 2016;4(40):6484-6496.

20. Morris SMJr. Arginine metabolism: boundaries of our knowledge. Journal of Nutrition. 2007;137(6 Suppl 2):1602S-1609S.

21. Tornatore L, Thotakura AK, Bennett J, Moretti M, Franzoso G. The nuclear factor kappa B signaling pathway: integrating metabolism with inflammation. Trends Cell Biol. 2012;22(11):557-566.

22. Hmil, DO, Mishhenko AV, Kostenko VO. Rol NO-sintazi $\mathrm{i}$ arginazi u mehanizmah okisno-nitrativnogo stresu $\mathrm{v}$ shkiri shhuriv za umov nadlishkovogo nadhodzhennja v organizm nitratu natriju. Ukrä̈nskij zhurnal medicini, biologiï ta sportu. 2017;2:54-59. (Ukrainian).

\title{
EFFICIENCY OF COMBINED APPLICATION OF L-ARGININE AND NUCLEAR FACTOR $K B$ INHIBITOR IN CORRECTING CONNECTIVE TISSUE DISRUPTION IN THE SKIN OF RATS UNDER EXCESSIVE SODIUM NITRATE INTAKE
}

\author{
Khmil D. A., Levkov A. A., Kostenko V. A.
}

Higher State Educational Institution of Ukraine "Ukrainian Medical Stomatological Academy",

Poltava, Ukraine

Objectives: to investigate the effects produced by the combined action of L-arginine and the NF- $\kappa B$ inhibitor ammonium pyrrolidine dithiocarbamate (PDTC) on the markers of connective tissue disruption in the skin of white rats and its biomechanical properties under excessive intake of sodium nitrate.

Material and methods. The studies were performed on 35 white Wistar rats. We assessed the concentration of collagenolysis and proteoglycans depolymerization products (free oxyproline, hexuronic acids) in the skin homogenate, as well as dermal tensometric characteristics.

Results. It has been found out that a 30-day administration of sodium nitrate is accompanied by the following changes in the skin tissues: enhancement of the processes of collagenolysis and proteoglycans depolymerization, impairment of biomechanical skin properties (strength and elasticity). It has been shown that the combined administration of L-arginine $(500 \mathrm{mg} / \mathrm{kg})$ and PDTC $(76 \mathrm{mg} / \mathrm{kg})$ once every three days starting from the 15th day of nitrate intoxication, demonstrates much more pronounced effects in reducing the concentration of free oxyproline and hexuronic acids in the skin homogenate and improving skin tensometric indicators as compared with their separate administration.

Conclusions. The combined effect of L-arginine and PDTC as a selective $N F-\kappa B$ inhibitor under nitrate intoxication is more effective than the isolated application of these substances. Their combined application limits the connective tissue disruption in the skin and improves its biomechanical properties.

Keywords: nitrate intoxication, nitric oxide cycle, collagenolysis, proteoglycans depolymerization, skin. 